\title{
Preferência de Bemisia tabaci biótipo B em linhagens mutantes de algodoeiro
}

\author{
Bemisia tabaci biotype B preference in mutant cotton lines \\ Francisco das Chagas Vidal Neto ${ }^{\mathrm{I}}$ Fanuel Pereira da Silva ${ }^{\mathrm{II}}$ Ervino Bleicher $^{\mathrm{II}}$ \\ Francisco Ivaldo Oliveira Melo ${ }^{\mathrm{II}}$
}

\section{RESUMO}

Os efeitos de caracteres mutantes morfológicos do algodoeiro (Gossypium hirsutum L. r. latifolium Hutch.): folha okra, bráctea frego e planta vermelha, em relação à resistência à mosca-branca (Bemisia tabaci biótipo B Hemiptera: Aleyrodidae), foram avaliados em experimentos com ou sem chance de escolha. Os experimentos foram conduzidos em casa-de-vegetação, no delineamento de blocos ao acaso, em fatorial $2^{3}+1$, com quatro repetições. O mutante com a característica planta vermelha foi menos atrativo e menos preferido para oviposição, em relação à planta verde, em ambos os ensaios, com ou sem escolha. Não houve preferência quanto à forma da folha e ao tipo de bráctea.

Palavras-chave: Gossypium hirsutum, mosca-branca, resistência de plantas a insetos.

\section{ABSTRACT}

The effects of cotton lines (Gossypium hirsutum $L$. r. latifolium Hutch.) with mutants morphologic characteristics: okra leaf, frego bract and red plant in relation to host plant resistance to whitefly (Bemisia tabaci bioyipe $\boldsymbol{B}$ Hemiptera: Aleyrodidae), were evaluated in choice or no choice assays. The assays were carried out in the greenhouse conditions, according to a completely randomized block design, in a $2^{3}+$ 1 in a factorial arrangement with four replications. The mutant with red plant characteristic was less attractive and less preferred for oviposition than the normal green plant does, in both, whit or without choice tests. It did not have preference in relation to the form of the leaf and bract type.

Key words: Gossypium hirsutum, whitefly, host plant resistance.

\section{INTRODUÇÃO}

O mecanismo de defesa do algodoeiro baseado em características morfológicas é de grande importância para o melhoramento genético da resistência às pragas e de grande potencial para o manejo da resistência às cultivares "Bt", através da piramidação gênica (SACHS et al., 1993). Características como: planta vermelha, folha okra e pilosidade têm-se apresentado como fatores de resistência a esta praga (THAXTON, EL-ZIK \& BIRD, 1985; CHU et al., 1998; CHU et al., 1999). Resultados obtidos por CHU et al. (2000) atribuem a ocorrência de menores populações de mosca-branca em algodões de folha okra à menor área foliar e à copa mais aberta destas plantas, criando um ambiente menos favorável. Dada a constatação de resistência parcial, a característica folha okra tem sido incorporada, isoladamente ou de forma combinada com outros fatores de resistência, em cultivares com base genética Pima (Gossypium barbadense L.), para uso em programas de melhoramento (PERCY, 2000). Por outro lado, foi constatada a suscetibilidade à moscabranca (Bemisia tabaci) em genótipos com folha okra, na presença de certas bases genéticas (BUTLER \& WILSON, 1984).

Este trabalho foi conduzido com o objetivo de avaliar os efeitos de características morfológicas, isoladamente ou associadas em um mesmo genótipo, como fontes de resistência à mosca-branca.

\footnotetext{
'Estação Experimental de Brabalha, Embrapa Algodão. Av. José Bernardino, km 4, 63180-000, Barbalha, CE, Brasil. E-mail: vidal@cnpa.embrapa.br. Autor para correspondência.

IIDepartamento de Fitotecnia, Centro de Ciências Agrárias, Universidade Federal do Ceará, Fortaleza, CE, Brasil.
} 


\section{MATERIAL E MÉTODOS}

Foram avaliadas oito linhagens quase isogênicas, em uma base genética REBA, e uma cultivar testemunha, "BRS 187 8H”, desenvolvida pela Embrapa Algodão, em relação à resistência à mosca-branca. As isolinhas incluíram todas as oito combinações homozigotas possíveis dos caracteres mutantes folha okra, bráctea frego e planta vermelha, com as equivalentes normais, obtidas no projeto de pesquisa conduzido na Universidade Federal do Ceará (UFC).

As avaliações foram realizadas em experimentos com e sem chance de escolha, conduzidos em casa-de-vegetação, na área experimental do Departamento de Fitotecnia do Centro de Ciências Agrárias da Universidade Federal do Ceará, em Fortaleza-CE, no ano 2000.

\section{Experimento com chance de escolha}

Neste experimento, cada bloco constou de uma gaiola coletiva, onde as parcelas, representadas por uma planta, foram dispostas em uma arena circular para estudos de verificação da atratividade ou preferência, de acordo com LARA (1991). As gaiolas, construídas com armação de ferro e revestidas com escaline, apresentavam as seguintes dimensões (altura - 0,5m; comprimento e largura - 1,0m). Tendo-se em vista reduzir a temperatura no interior das gaiolas, colocou-se um anteparo de Sombrite 30\%.

As plantas foram cultivadas em tubetes, contendo substrato de terra vegetal + vermiculita, e recebiam irrigação duas vezes por dia e adubação semanal.

As infestações foram realizadas com as plantas no estágio de 4 a folha definitiva expandida, tendo em vista que apenas a partir da 3 a folha é que ocorreu a diferenciação da folha okra. Foram empregados 20 exemplares de adultos de $\boldsymbol{B}$. tabaci para cada planta (180 adultos gaiola $\left.{ }^{-1}\right)$, conforme SERRA (1986). Os insetos foram criados artificialmente em meloeiro (Cucumis melo L.) e, antes da liberação nas gaiolas, foram eliminadas as duas primeiras folhas das plantas, deixando-se apenas a $3^{\mathrm{a}}$ e a 4 a .

A liberação foi realizada cedo pela manhã e os insetos mantidos pelo período de 48 horas, sobre as plantas. As contagens dos adultos pousados na face ventral das folhas foram realizadas às 4, 24 e 48 horas após a infestação. Ao final das 48 horas, os insetos adultos foram retirados e passou-se a realizar as contagens do número de ovos colocados na $4^{a}$ folha.

$\mathrm{O}$ experimento foi repetido, visando-se a aumentar o número de repetições e a melhorar a precisão experimental.
Os dados foram analisados segundo o delineamento de blocos ao acaso, com quatro repetições, em fatorial $2^{3}+1$, em que os fatores eram representados pelas características morfológicas para folha, bráctea e cor, e os níveis pelos estados mutante e normal. $\mathrm{O}$ tratamento adicional foi representado pela testemunha, a cultivar "BRS 187 8H". Foi realizada a análise de variância conjunta para os dois experimentos com os dados transformados para $\sqrt{\mathrm{X}}$.

\section{Experimento sem chance de escolha}

O experimento foi conduzido em casa-devegetação e manteve os mesmos tratamentos e delineamento do experimento com chance de escolha. As parcelas corresponderam aos tratamentos e foram representadas por uma gaiola contendo uma planta.

As gaiolas individuais foram construídas de material plástico, com janelas e o teto de escaline, para proporcionar ventilação e permitir a introdução dos insetos. As dimensões foram: altura $=50 \mathrm{~cm}$ e $\phi=25 \mathrm{~cm}$. As plantas foram cultivadas em vasos plásticos (volume-10l), em substrato de solo+areia+esterco de gado, na proporção de 1:1:1 e receberam uma adubação de base segundo a fórmula 30-40-20 de N-P-K.

As infestações foram realizadas no estágio de $4^{\mathrm{a}}$ folha, com 20 adultos gaiola $^{-1}$ (Experimento 1), após serem eliminadas as duas primeiras folhas. A contagem do número de insetos pousados sobre as parcelas foi realizada 48 horas após a infestação, ocasião em que os insetos eram retirados das gaiolas e se iniciavam a contagem dos ovos depositados na $4^{\mathrm{a}}$ folha. Após a coleta dos dados, observou-se um baixo número de insetos pousados e de ovos colocados. Considerando-se esses aspectos, optou-se pela condução de um novo experimento (Experimento 2), aumentando-se para 30 o número de insetos por gaiola.

A análise de variância conjunta dos dados foi realizada segundo o delineamento de blocos ao acaso, com parcelas subdividas e quatro repetições. As parcelas constaram das isolinhas, além de uma testemunha adicional representada pela variedade comercial "BRS 187 8H". As subparcelas constaram do número de insetos adultos liberados por gaiola. Os dados forma transformados para $\sqrt{\mathrm{x}}$ e as comparações foram feitas pelo teste F. Para avaliar a relação entre o número de insetos pousados e o número de ovos depositados, nos diferentes períodos, foi realizada a análise de regressão.

\section{RESULTADOS E DISCUSSÃO}

Os dados obtidos nos experimentos apresentaram alta variação. Este comportamento foi 
mais acentuado nos ensaios com chance de escolha, onde os coeficientes de variação (CV) foram, no mínimo, $10 \%$ superiores. ALEXANDER et al. (2004) observaram números médios sazonais de adultos, ninfas e ovos de B. tabaci altamente variáveis entre e dentro de cor e forma da folha e pilosidade, em algodoeiro. A mudança da espécie hospedeira, bem como as diferenças morfológicas das plantas do algodoeiro, dificultando o processo seletivo do inseto, uma vez que estes foram criados em meloeiro (Cucumis melo L.), certamente contribuíram para isso. Segundo SERRA (1996), os indivíduos de B. tabaci precisam habituar-se, antes de ovipositarem.

A grande variabilidade no número total de ovos entre experimentos, bem como entre gaiolas, foi atribuída por SIMMONS (1994) ao uso de fêmeas de diferentes idades. Resultados obtidos por BLEICHER (2004 - informe verbal), trabalhando com repolho verde e roxo, em ensaio com chance de escolha, indicaram que a variação na cor das plantas resultou em maior tempo (72 horas) necessário para o inseto definir a seleção da planta. De modo semelhante, neste trabalho, apenas a partir da contagem de adultos, 24 horas após a infestação, foi possível observar uma melhor discriminação dos tratamentos por parte do inseto.

Nos dois experimentos com chance de escolha, observaram-se coeficientes de correlação geral média altamente significativos, $\mathrm{r}=0,84^{* *}$ (4 horas), $\mathrm{r}=$ $0,83^{* *}$ ( 24 horas) e $0,86^{* *}$ ( 48 horas), entre o número de adultos pousados e o número de ovos colocados. Esses valores indicam a tendência de os indivíduos de mosca-branca ovipositarem nas plantas onde pousaram, o que pode ser mais bem observado na figura 1. Segundo LENTEREN \& NOLDUS (1990), isto se deve ao fato de que a seleção do substrato para oviposição é uma fase crítica no ciclo de vida das moscas-brancas, pois, na maioria das espécies, os estágios larvais são completamente imóveis, exceto no primeiro ínstar e, por isso, elas apresentam limitada capacidade de dispersão na folha onde colocaram os ovos. Isto indica que a seleção do local de oviposição apresenta significativo efeito no seu desempenho. Daí a razão de a maioria das espécies de mosca-branca alimentarem-se e ovipositarem nas mesmas folhas.

Nos três períodos de contagens de adultos, observou-se comportamento semelhante. Apesar da não-significância para cor da planta na contagem 4 horas após infestação, na análise dos quadrados médios do número de adultos pousados, referentes ao levantamento realizado quatro horas após a infestação (Tabela 1), observou-se que o Teste $\mathrm{F}$ foi altamente significativo para tratamento, principalmente, devido ao efeito do contraste testemunha versus linhagens, no qual a testemunha foi a preferida. Quanto à interação bráctea x cor da planta, a combinação planta vermelhabráctea normal $\left(8,31\right.$ adultos planta $\left.{ }^{-1}\right)$ apresentou menor número de adultos pousados do que a planta verdebráctea normal (12,5 adultos planta $\left.{ }^{-1}\right)$. A linhagem com a combinação planta verde-bráctea "frego" foi menos preferida (8,70 adultos planta $\left.{ }^{-1}\right)$ do que a planta verdebráctea normal $\left(12,15\right.$ adultos planta $\left.{ }^{-1}\right)$.

Na avaliação realizada 24 horas após a infestação (Tabela 1), o Teste $\mathrm{F}$ foi altamente significativo para tratamento, testemunha versus linhagens, cor da planta, interação tipo de bráctea x cor da planta e experimento. A característica planta vermelha (8,00 adultos planta $\left.^{-1}\right)$ mostrou-se significativamente menos preferida em relação à planta verde (11,06 adultos planta $\left.^{-1}\right)$. ALEXANDER et al. (2004) observaram que genótipos de algodão com planta vermelha tinham menos adultos, ovos e ninfas do que aqueles com planta normal verde, embora não significativamente. A cor é o fator mais importante para a seleção do hospedeiro a distância, pela mosca-branca, cujo mecanismo de percepção permite a distinção até mesmo de matizes semelhantes à folhagem das plantas (PROKOPY \& OWENS, 1983; LENTEREN \& NOLDUS, 1990). Segundo CHU et al. (2000), as cores mais atrativas para B. tabaci assemelham-se ao espectro de reflectância da face inferior das folhas do algodoeiro.

A interação tipo de bráctea x cor da planta foi significativa, com a linhagem bráctea frego-planta verde apresentando uma redução do número de adultos pousados de 13,10 para 9,24, em relação à bráctea normal. A linhagem bráctea frego-planta vermelha não teve nenhum efeito sobre o número de adultos pousados $(8,51)$, em relação à bráctea normal $(7,51)$.

A análise conjunta do levantamento 48 horas após a infestação (Tabela 1) produziu resultados semelhantes ao levantamento 24 horas após, no qual o teste $\mathrm{F}$ foi significativo para cor da planta e para a interação tipo de bráctea x cor da planta. O estudo da interação também produziu resultados semelhantes.

Os resultados em relação à bráctea "frego" não eram esperados, a não ser por efeito secundário produzido sobre a textura da folha ou deformação desta em relação ao tipo normal, como sugere PENNA (1999).

A análise de variância conjunta do número de ovos colocados apresentou valor de F altamente significativo para tratamento, principalmente devido ao contraste testemunha versus fatorial, como se observa na tabela de quadrados médios (Tabela 1). A testemunha (76,56 ovos planta $\left.{ }^{-1}\right)$ foi mais preferida para oviposição em relação à média das linhagens (36,36 ovos planta $\left.{ }^{-1}\right)$. O menor número de ovos colocados na linhagem com características morfológicas normais 


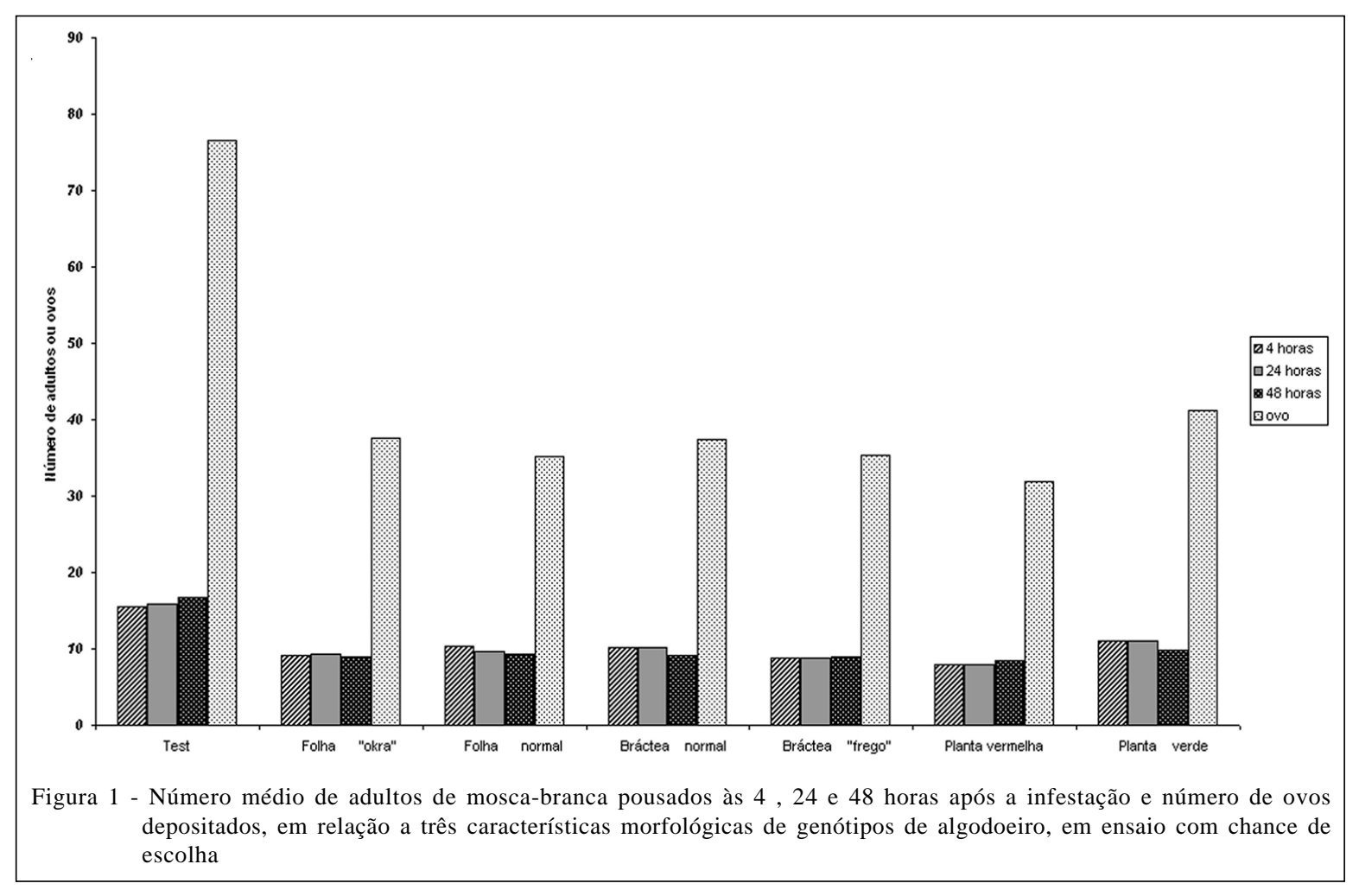

Tabela 1 - Análise de variância conjunta do número de ovos depositados e número de adultos de mosca-branca pousados, nas avaliações às 4 , 24 e 48 horas após a infestação, em relação a três características morfológicas de genótipos de algodoeiro, em ensaio com chance de escolha.

\begin{tabular}{|c|c|c|c|c|c|}
\hline \multirow{2}{*}{ Causas de variação } & \multirow{2}{*}{ GL } & \multicolumn{4}{|c|}{ Quadrado médio $^{1}$} \\
\hline & & 4 horas & 24 horas & 48 horas & ovos \\
\hline Bloco/experimento & 6 & $0,14^{\mathrm{ns}}$ & $0,15^{\text {ns }}$ & $1,18^{* *}$ & $3,30^{\text {ns }}$ \\
\hline Tratamento & [8] & $1,20 * *$ & $1,67 * *$ & $1,22 * *$ & $8,29 * *$ \\
\hline Test. vs linhagens & 1 & $4,74^{* *}$ & $6,04 * *$ & $7,48 * *$ & $53,17 * *$ \\
\hline Fatorial & (7) & $0,69^{\mathrm{ns}}$ & $1,05^{*}$ & $0,32^{\text {ns }}$ & $1,88^{\mathrm{ns}}$ \\
\hline Forma da folha (A) & 1 & $0,55^{\mathrm{ns}}$ & $0,01^{\mathrm{ns}}$ & $0,03^{\mathrm{ns}}$ & $0,55^{\mathrm{ns}}$ \\
\hline Tipo de bráctea (B) & 1 & $0,18^{\mathrm{ns}}$ & $0,65^{\mathrm{ns}}$ & $0,22^{\mathrm{ns}}$ & $0,95^{\mathrm{ns}}$ \\
\hline Cor da planta (D) & 1 & $0,48^{\mathrm{ns}}$ & $3,96 * *$ & $0,95 *$ & $8,18 * *$ \\
\hline$A \times B$ & 1 & $0,001^{\text {ns }}$ & $0,28^{\text {ns }}$ & $0,06^{\mathrm{ns}}$ & $0,27^{\text {ns }}$ \\
\hline$A \times D$ & 1 & $0,64^{\mathrm{ns}}$ & $0,11^{\mathrm{ns}}$ & $0,04^{\mathrm{ns}}$ & $0,09^{\mathrm{ns}}$ \\
\hline$B \times D$ & 1 & $2,95^{* *}$ & $2,30 * *$ & $0,97 *$ & $2,73^{\mathrm{ns}}$ \\
\hline$A \times B \times D$ & 1 & $0,05^{\text {ns }}$ & $0,03^{\text {ns }}$ & $0,00^{\mathrm{ns}}$ & $0,02^{\mathrm{ns}}$ \\
\hline Experimento & 1 & $0,69^{\mathrm{ns}}$ & $2,84 * *$ & $1,12 *$ & $3,85^{\mathrm{ns}}$ \\
\hline Tratam. X exp. & 8 & $0,35^{\mathrm{ns}}$ & $0,2^{\mathrm{ns}}$ & $0,12^{\mathrm{ns}}$ & $0,94^{\mathrm{ns}}$ \\
\hline Resíduo & 48 & 1,04 & 1,09 & 0,92 & 4,69 \\
\hline CV (\%) & & 31,2 & 32,82 & 30,71 & 34,16 \\
\hline
\end{tabular}

${ }^{1}$ Dados transformados para $\sqrt{\mathrm{x}}$.

** Significativo ao nível de probabilidade de $1 \%$ pelo teste $\mathrm{F}$.

* Significativo ao nível de probabilidade de $5 \%$ pelo teste $\mathrm{F}$.

${ }^{\text {ns }}$ Não significativo. 
pode significar também um efeito da base genética Reba, em relação à testemunha. Efeitos da base genética foram observados por BUTTLER \& WILSON (1984) e BUTTLER et al. (1986).

Na análise de variância conjunta do número de adultos pousados do ensaio sem chance de escolha (Tabela 2), o teste $\mathrm{F}$ foi significativo para as causas de variação experimento ( $\mathrm{n}^{-}$de insetos gaiola ${ }^{-1}$ ) e para a interação experimento x cor da planta. Mesmo não apresentando diferença significativa para cor da planta, observa-se maior número de insetos adultos nas plantas de cor verde.

O número médio de adultos pousados no experimento 1 (20 insetos gaiola ${ }^{-1}$ ) foi de 4,41 , enquanto que no experimento 2 (30 insetos gaiola ${ }^{-1}$ ) foi de 10,76. A análise dos dados dos experimentos individuais mostrou que o aumento do número de insetos de 20 para 30/gaiola reduziu o coeficiente de variação de $27,43 \%$ para $18,87 \%$, melhorando a uniformidade e possibilitando melhor discriminação dos resultados. O estudo da interação experimento x cor da planta revelou que não houve diferença significativa em relação à cor da planta, quando o número de insetos foi de 20 gaiola $^{-1}$ (E1). O aumento para 30 insetos gaiola ${ }^{-1}$ permitiu a diferenciação em relação à resposta da cor da planta ao número de adultos pousados, sendo a planta vermelha foi menos preferida (8,16 adultos pousados) do que a planta verde (13,11 adultos pousados).

A análise de variância conjunta do número de ovos colocados no experimento sem chance de escolha apresentou comportamento semelhante ao número de adultos pousados, exceto para a interação tratamento x experimento, que foi altamente significativa (Tabela 2). O número médio de ovos colocados por planta no experimento $1(6,45)$ diferiu significativamente daquele do experimento 2 (39,31). O estudo da interação tratamento x experimento permitiu detectar diferença altamente significativa em relação ao fator cor da planta. No experimento 1 , não foi possível detectar diferença em relação à preferência, pela planta vermelha $(6,45$

Tabela 2 - Análise de variância conjunta do número de ovos depositados e número de adultos de mosca branca pousados, em relação a três características morfológicas de genótipos de algodoeiro, em ensaio sem chance de escolha.

\begin{tabular}{llcc}
\hline & GL & & Quadrado médio $^{1}$ \\
\cline { 3 - 4 } Causas de variação & & $\mathrm{N}^{\text {o }}$ ovos colocados & $\mathrm{N}^{\text {o }}$ adultos pousados \\
\hline Tratamento & {$[8]$} & $10,26^{\text {ns }}$ & $0,63^{\text {ns }}$ \\
Testemunha vs linhagens & 1 & $22,84^{\text {ns }}$ & $0,89^{\text {ns }}$ \\
Fatorial & $(7)$ & $8,46^{\text {ns }}$ & $0,59^{\text {ns }}$ \\
Folha (A) & 1 & $9,27^{\text {ns }}$ & $0,37^{\text {ns }}$ \\
Bráctea (B) & 1 & $2,64^{\text {ns }}$ & $0,02^{\text {ns }}$ \\
Cor (D) & 1 & $38,37^{*}$ & $2,64^{\text {ns }}$ \\
AxB & 1 & $5,45^{\text {ns }}$ & $0,12^{\text {ns }}$ \\
AxD & 1 & $3,14^{\text {ns }}$ & $0,02^{\text {ns }}$ \\
BxD & 1 & $0,34^{\text {ns }}$ & $0,04^{\text {ns }}$ \\
AxBxD & 1 & $0,03^{\text {ns }}$ & $0,90^{\text {ns }}$ \\
Experimento & 1 & $280,99 * *$ & $22,06^{* *}$ \\
Experimento x tratamento & {$[8]$} & $7,06^{* *}$ & $0,62^{\text {ns }}$ \\
Experim vs test. vs linhagens & 1 & $7,51^{* *}$ & $0,008^{\text {ns }}$ \\
Experimento x fatorial & $(7)$ & $7,00^{* *}$ & $4,94^{\text {ns }}$ \\
Exp. x Forma da folha (A) & 1 & $0,02^{\text {ns }}$ & $0,63^{\text {ns }}$ \\
Exp. x tipo de bráctea (B) & 1 & $4,71^{\text {ns }}$ & $0,90 \mathrm{~ns}$ \\
Exp. x cor da planta (D) & 1 & $38,49^{* *}$ & $2,06^{*}$ \\
Exp. x A x B & 1 & $3,50^{\text {ns }}$ & $0,02^{\text {ns }}$ \\
Exp. x A x D & 1 & $0,65^{\text {ns }}$ & $0,002^{\text {ns }}$ \\
Exp. x B x D & 1 & $1,40^{\text {ns }}$ & $1,01^{\text {ns }}$ \\
Exp. x A x B x D & 1 & $0,22^{\text {ns }}$ & $0,32^{\text {ns }}$ \\
Resíduo & 48 & 1,59 & 0,36 \\
CV (\%) & & 27,38 & 22,30 \\
\hline
\end{tabular}

\footnotetext{
${ }^{1}$ Dados transformados para $\sqrt{\mathrm{x}}$.

** significativo a $1 \%$ de probabilidade pelo teste $\mathrm{F}$.

* significativo a 5\% de probabilidade pelo teste $\mathrm{F}$.

ns Não significativo.
} 
ovos planta $\left.{ }^{-1}\right)$ ou planta verde (6,45 ovos planta $\left.{ }^{-1}\right)$, em relação ao número de ovos colocados. No experimento 2, houve preferência para oviposição na planta verde (61,15 ovos planta $\left.{ }^{-1}\right)$, em relação à vermelha (22,28 ovos planta $\left.^{-1}\right)$. O aumento do número de adultos por gaiola de 20 (experimento 1) para 30 (experimento 2) aumentou significativamente o número de ovos colocados, em relação a ambos os tipos de plantas, sendo relativamente maior nas plantas verdes.

Estes resultados indicam que o número de insetos por gaiola influencia a avaliação do processo de escolha e, de acordo com as condições do ensaio e os resultados obtidos, o emprego de 30 insetos gaiola $^{-1}$ deve ser preferido. Segundo LARA (1991), de modo geral, baixas ou altas populações do inseto podem dificultar a diferenciação entre tratamentos resistentes e suscetíveis, por acarretarem poucos danos ou danos excessivos, respectivamente, nivelando o comportamento dos genótipos testados. Para SERRA (1996), a forma e o tamanho das gaiolas dependem dos objetivos da pesquisa, da criatividade do pesquisador e do material e recursos disponíveis. Entretanto, elas devem permitir a observação fácil dos insetos, não ocupar muito espaço e serem baratas. Para estudo de preferência do hospedeiro, o autor recomenda colocar-se 3 a 10 plantas por gaiola, individuais ou coletivas, liberandose 20 adultos por planta. Para plantas individuais, as gaiolas devem ter de 0,04 a $0,13 \mathrm{~m}^{3}$.

\section{CONCLUSÕES}

A característica mutante planta vermelha manifesta-se menos atrativa e menos preferida para oviposição de $\boldsymbol{B}$. tabaci biótipo $\mathrm{B}$, em relação à planta verde.

As características folha okra e bráctea frego comportam-se como neutras, em relação à preferência.

\section{AGRADECIMENTOS}

Ao Conselho Nacional de Desenvolvimento Científico e Tecnológico (CNPq), pela concessão de bolsa de estudos.

\section{INFORME VERBAL}

Bleicher, E.

\section{REFERÊNCIAS}

ALEXANDER, P.J. et al. Preliminary screening of different cottons for resistance to sweetpotato whitefly infestations. In: Arizona Cotton REPORT (P-138). Tucson, College of Agriculture/University of Arizona. 2004. p.209-212. Capturado em 21 mar. 2005. Online. Disponível na internet http:// cals.arizona.edu/pubs/crops/az1335/ az13357a.pdf.
BUTLER, G.D.J.; WILSON, F.D. Activity of adult whiteflies (Homoptera: Aleyrodidae) within plantings of different cottons strains and cultivars as determined by stick-trap catches. Journal of Economic Entomology, v.77, n.5, p.1137-1140, 1984

BUTLER, G.D.J. et al. Bemisia tabaci (Homoptera: Aleyrodidae) on cotton: adult activity and cultivar oviposition preference. Journal of Economic Entomology, v.79, n.2, p.350-354, 1986.

CHU, C.C. et al. Silverlef whitefly cotton cultivar preference. In: Cotton: A College of Agriculture report for 1998. Report, Tucson, College of Agriculture/University of Arizona, 1998. Capturado em 28 ago. 1999. Online. Disponível na internet http://ag.arizona.edu/pubs/crops/az1006/az10067m.html.

CHU, C.C. et al. Bemisia tabaci (Hemiptera: Aleyrodidae) biotype $\mathrm{B}$ colonisation and leaf morphology relationships in upland cotton cultivars. Australian Journal of Entomology, Canberra, v.38, n.2, p.127-131, 1999.

CHU, C.C. et al. Susceptibility of normal-leaf and okra-leaf shape cottons to silverleaf whiteflies and relationships to trichome densities. In: BELTWIDE COTTON CONFERENCES, 1983-2001, San Antonio. Proceedings... Memphis: National Cotton Council, 2000. p.1157-1158. CD ROM.

LARA, F.M. Princípios de resistência de plantas a insetos. 2.ed. São Paulo: Ícone, 1991. 336p.

LENTEREN, J.C.Van; NOLDUS, L.P.J.J. Whitefly - plant relationships: behavioral and ecological aspects. In: GERLING, D. (Ed.). Whiteflies: their bionomics, pest status and management. Andover, UK: Intercept, 1990. p.47-89.

PENNA, J.C.V. Melhoramento do algodão. In: BORÉM, A. (Ed.). Melhoramento de espécies cultivadas. Viçosa: UFV, 1999. p.15-50.

PROKOPY, R.J.; OWENS, E.D. Visual detection of plants by herbivorous insects. Annual Review of Entomology, Palo Alto, v.28, p.337-364, 1983.

PERCY, R.G. Release of okra-leaf, nectariless, and okra-leafnectariless pima germplasm lines in full season and early maturing backgrounds. In: BELTWIDE COTTON PODUCTION RESEARCH CONFERENCES, 2000, San Antonio. Proceedings... Memphis: National Cotton Council, 2000. V.1, p.524-525.

SACHS, E.S. et al. Gene pyramiding to improve resistance to insects in cotton expressing the cry/A gene. In: BELTWIDE COTTON PODUCTION RESEARCH CONFERENCES, 1993, New Orleans. Proceedings... Memphis: National Cotton Council, 1993. V.2, p.808-813.

SERRA, C.A. Biologia de moscas blancas. In: HILJE, L. (Ed.). Metodologias para el estudio y manejo de moscas blancas y geminivirus. Turrialba: CATIE, 19986. 133p. (Serie Materiales de Ensenhanza, 37).

SIMMONS, A.M. Oviposition on vegetables by Bemisia tabaci (Homoptera aleyrodidae): temporal and leaf surface factors. Environmental Entomology, v.23, n.2, p.382-389, 1994.

THAXTON, P.M. et al. Influence of glabrous and hairy plants, leaf and bracts types of near-isogenic cotton lines on lint yield, earliness, and fiber quality. In: BELTWIDE COTTON PRODUCTION RESEARCH CONFERENCES, 1985, New Orleans. Proceedings... Memphis: National Cotton Council, 1985. p.81-84. 